\title{
Giant changes in atomic dynamics on microalloying metallic melt
}

\author{
S. M. Chathoth, ${ }^{1, a)}$ B. Damaschke, ${ }^{1}$ J. P. Embs, ${ }^{2}$ and K. Samwer ${ }^{1}$ \\ ${ }^{1}$ I. Physikalisches Institut, Georg-August-Universität, 37077 Göttingen, Germany \\ ${ }^{2}$ Laboratory for Neutron Scattering, ETH Zurich, Paul Scherrer Institut, CH-5232 Villigen, Switzerland \\ and Physical Chemistry, Saarland University, D-66123 Saarbrcken, Germany
}

(Received 9 October 2009; accepted 24 October 2009; published online 13 November 2009)

\begin{abstract}
We report unexpectedly strong variations in the relaxational dynamics in a glass-forming metallic melt while microalloying. Analysis of quasielastic neutron scattering data revealed that changes in the values of stretching of the self-correlation function and the temperature dependence of self-diffusivity showed an Arrhenius to non-Arrhenius transition. The intermediate structure of the melts did not show any prepeak or indication of short range order. These observations are correlated with the enhanced glass-forming ability of metallic melts on microalloying. () 2009 American Institute of Physics. [doi:10.1063/1.3263950]
\end{abstract}

Bulk metallic glasses (BMG) are a rather new class of materials that have significant scientific and technological importance. ${ }^{1-3}$ There have been many efforts to develop new BMG with superior glass-forming ability (GFA). However, due to the complexity of glass-formation obtaining a full understanding of GFA remains a challenge and applications of BMG are still limited due to their poor GFA. To describe the GFA of a metallic system several empirical criteria based on structure, thermodynamics, and kinetic have been proposed. ${ }^{1-5}$ These criteria are based on experimental results of frozen glass itself and are not found to hold in general. Recently it was discovered that certain alloy systems show a dramatic increase in GFA while microalloying. ${ }^{6}$ Thermophysical properties such as density, viscosity, or electrical properties, etc. did not change significantly while microalloying. ${ }^{6,7}$ The reason for such a huge increase in the GFA has not yet been established. ${ }^{6}$ Here we investigated such a glass-forming system using quasielastic neutron scattering (QENS) in order to understand the changes in the atomic dynamics while microalloying and the correlation with the GFA.

Recently developed cerium based glass-forming alloys show an exceptionally low glass-transition temperature and excellent GFA. ${ }^{8,9}$ We chose this alloy system for the following reasons: (1) While microalloying, the critical casting thickness increases up to $80 \%$. For example, replacing $1 \%$ of Ce by $\mathrm{Nb}$ in $\mathrm{Ce}_{70} \mathrm{Cu}_{20} \mathrm{Al}_{10}$ the critical casting diameter increases from $2 \mathrm{~mm}$ to $10 \mathrm{~mm}^{9}$. (2) The change in glass transition temperature $\left(T_{g}\right)$, crystallization temperature $\left(T_{x}\right)$, and the liquidus temperature $\left(T_{l}\right)$ in microalloying is only a few degrees Kelvin (see Table I). (3) The reason for the increase in the critical casting diameter cannot be explained by the kinetic or thermodynamic models or empirical relations mentioned above. ${ }^{6}$ (4) In this alloy systems only the $\mathrm{Cu}$ atoms possess an incoherent neutron scattering cross-section, hence the changes in the dynamics of $\mathrm{Cu}$ while microalloying can be investigated.

QENS experiments were carried out on the time-of-flight spectrometer FOCUS at the Paul Scherrer Institut, Switzerland. We used a 5.4 A neutron wavelength providing a wavenumber range $(q)$ at zero energy transfer of 0.4 to $2.0 \AA^{-1}$,

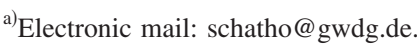

with an energy resolution of $\simeq 130 \mu \mathrm{eV}$. The $q$ range in our experimental setup was less than structure factor maximum, $q_{0}\left(q_{0}=2.4 \AA^{-1}\right)$, hence coherent scattering were suppressed. Thus, the scattered signals in our experiments were dominated by the incoherent scattering from $\mathrm{Cu}$ atoms. The resulting self-correlation functions $\Phi(q, t)$ represent the mean dynamics of $\mathrm{Cu}$ atoms in the melts. The samples were measured at room temperature to obtain the instrumental energy resolution function, close to the melting temperature $\left(T_{m}\right)$, $850 \mathrm{~K}$, and 5 more temperatures up to $1350 \mathrm{~K}$ with a step interval of $100 \mathrm{~K}$.

The scattering law, $S(q, \omega)$, was determined by normalizing the raw data to a vanadium standard, correcting for self-absorption and container scattering, interpolating to constant $q$, and symmetrizing with respect to energy with the detailed balance factor. Fourier deconvolution of $S(q, \omega)$ and normalization to one for $t=0$ gives $\Phi(q, t)$. Figures $1(\mathrm{a})$ and 1(b) display $\Phi(q, t)$ of the liquid $\mathrm{Ce}_{70} \mathrm{Cu}_{20} \mathrm{Al}_{10}$ and $\mathrm{Ce}_{69} \mathrm{Cu}_{20} \mathrm{Al}_{10} \mathrm{Nb}_{1}$, respectively, at $q=1.09 \AA^{-1}$. $\Phi(q, t)$ in the $\alpha$-relaxation regime was fitted with Kohlrausch-WilliamsWatts (KWW) function,

$$
\Phi(q, t)=f_{q} \exp \left[\left(-t / \tau_{q}\right)^{\beta_{\alpha}}\right] .
$$

The $\Phi(q, t)$ of $\mathrm{Ce}_{70} \mathrm{Cu}_{20} \mathrm{Al}_{10}$ melt obtained at $850 \mathrm{~K}$ can be well fitted with KWW function with a $\beta_{\alpha}$ value of $0.70 \pm 0.04$. On increasing the temperature the value of $\beta_{\alpha}$ increases and at $1350 \mathrm{~K}$ its value was found to be $0.90 \pm 0.04$. Similarly, for liquid $\mathrm{Ce}_{70} \mathrm{Cu}_{20} \mathrm{Al}_{10} \mathrm{Nb}_{1}, \beta_{\alpha}$ varies from $0.50 \pm 0.04$ at $850 \mathrm{~K}$ to $0.88 \pm 0.04$ at $1350 \mathrm{~K}$. A clear temperature dependence on stretching of structural relaxation is observed in these liquids. Figure 2(a) shows the temperature dependence of $\beta_{\alpha}$ obtained from the KWW fit in the above melts. Mode-coupling theory gives a microscopic explanation for stretching in terms of a nonlinear coupling

TABLE I. The critical thickness $d_{c}$ and the thermal parameters $T_{g}, T_{x}$, and $T_{l}$ of the samples (taken from Ref. 9)

\begin{tabular}{lcccc}
\hline \hline \multicolumn{1}{c}{ Sample } & $\begin{array}{c}d_{c} \\
(\mathrm{~mm})\end{array}$ & $\begin{array}{c}T_{g} \\
(\mathrm{~K})\end{array}$ & $\begin{array}{c}T_{x} \\
(\mathrm{~K})\end{array}$ & $\begin{array}{c}T_{l} \\
(\mathrm{~K})\end{array}$ \\
\hline $\mathrm{Ce}_{70} \mathrm{Cu}_{20} \mathrm{Al}_{10}$ & 2 & 341 & 408 & 722 \\
$\mathrm{Ce}_{69} \mathrm{Cu}_{20} \mathrm{Al}_{10} \mathrm{Nb}_{1}$ & 10 & 352 & 412 & 728 \\
\hline \hline
\end{tabular}




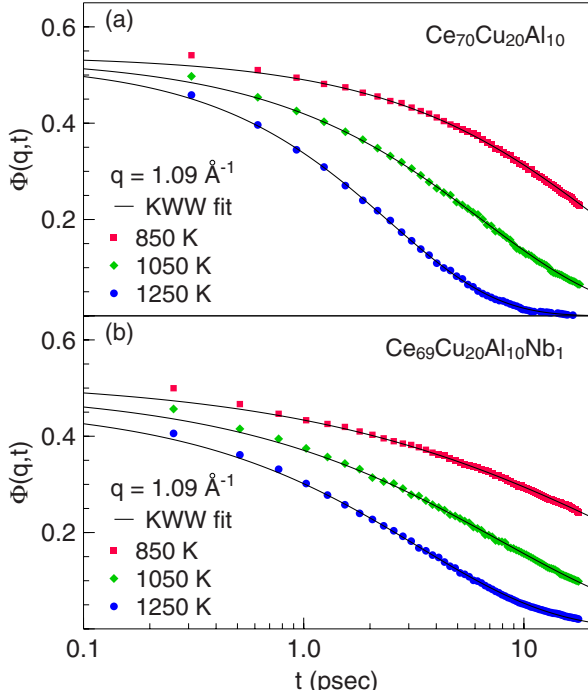

FIG. 1. (Color online) The self-correlation function $\Phi(q, t)$ of $\mathrm{Cu}$ atoms in liquids $\mathrm{Ce}_{70} \mathrm{Cu}_{20} \mathrm{Al}_{10}$ and $\mathrm{Ce}_{69} \mathrm{Cu}_{20} \mathrm{Al}_{10} \mathrm{Nb}_{1}$ at three different temperature and the solid lines are fit with KWW function.

of density fluctuations caused by feedback effects in dense liquids. ${ }^{10}$ The larger stretching observed for liquid $\mathrm{Ce}_{69} \mathrm{Cu}_{20} \mathrm{Al}_{10} \mathrm{Nb}_{1}$ indicates an increase in feedback compared to "pure" $\mathrm{Ce}_{69} \mathrm{Cu}_{20} \mathrm{Al}_{10}$. Integrating $S(q, \omega)$ over the elastic line gives structural information at intermediate length scales. Figure 2(b) shows $S(q)$ of both liquids measured at 850 and $1350 \mathrm{~K}$. Neither of the liquids showed any prepeak as we observed in Al-Ni systems. ${ }^{11}$ This indicates that there is no significant short range ordering and the intermediate structure of the liquids did not change while microalloying.

The mean relaxation time from the KWW fitting obtained by

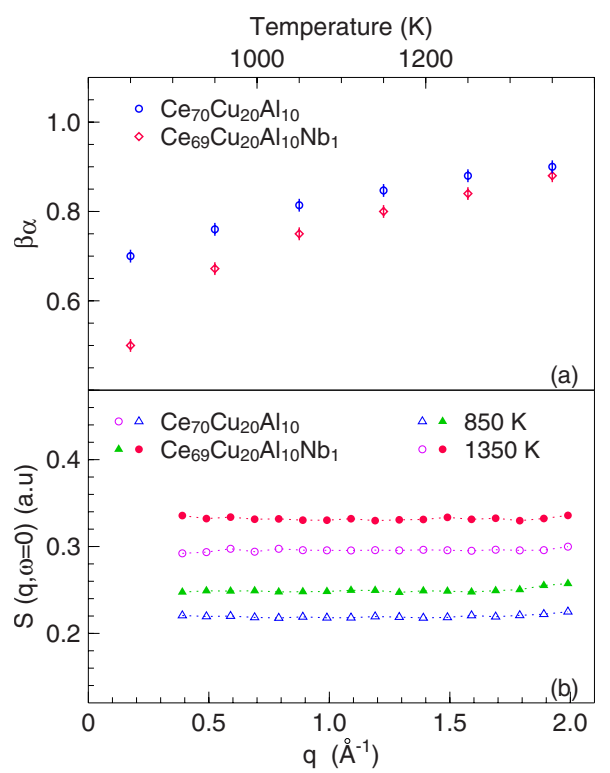

FIG. 2. (Color online) (a) The temperature dependence of stretching exponent $\beta_{\alpha}$ obtained from the KWW fitting to the $\Phi(q, t)$. (b) The intermediate structure factor of liquids $\mathrm{Ce}_{70} \mathrm{Cu}_{20} \mathrm{Al}_{10}$ and $\mathrm{Ce}_{69} \mathrm{Cu}_{20} \mathrm{Al}_{10} \mathrm{Nb}_{1}$ obtained by integrating $S(q, \omega=0)$ over the elastic line.

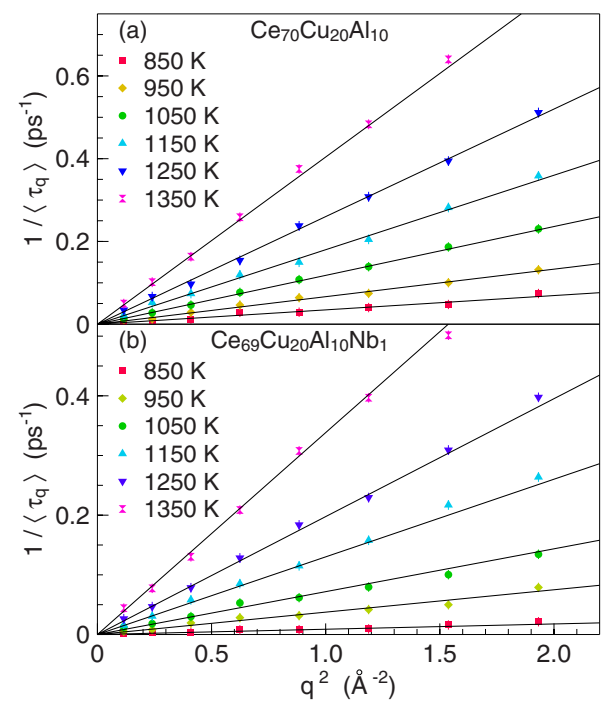

FIG. 3. (Color online) $q^{2}$ depends on inverse of $\langle\tau\rangle$ of $\mathrm{Cu}$ atoms in the liquids $\mathrm{Ce}_{70} \mathrm{Cu}_{20} \mathrm{Al}_{10}$ and $\mathrm{Ce}_{69} \mathrm{Cu}_{20} \mathrm{Al}_{10} \mathrm{Nb}_{1}$ obtained for six different temperatures. At $q$ values, $q \ll q_{0}$ shows a linear dependence. The straight lines are the linear fit and the slope gives the self-diffusion coefficient.

$$
\left\langle\tau_{q}\right\rangle=\int_{0}^{\infty} \Phi(q, t) / f_{q}=\tau_{q} \beta_{q}^{-1} \Gamma\left(\beta_{q}^{-1}\right),
$$

where $\Gamma$ is the gamma function. $\left\langle\tau_{\alpha}\right\rangle$ is proportional to $q^{-2}$ as expected in the hydrodynamic limit for $q \ll q_{0}{ }^{12}$ This enables us to determine the average self-diffusivity.

$$
D=\frac{1}{q^{2}\left\langle\tau_{q}\right\rangle}
$$

Figures 3(a) and 3(b) show $q^{2}$ dependence of $\left\langle\tau_{\alpha}\right\rangle$ of $\alpha$-process and the data points are fitted with a straight line and the slope gives the $D$. Figure 4 shows the self-diffusivity of $\mathrm{Cu}$ in the liquids $\mathrm{Ce}_{70} \mathrm{Cu}_{20} \mathrm{Al}_{10}$ and $\mathrm{Ce}_{70} \mathrm{Cu}_{20} \mathrm{Al}_{10} \mathrm{Nb}_{1}$. At the highest measured temperature $(1350 \mathrm{~K})$, the value of $D$ shows $3.33 \pm 0.16 \times 10^{-9} \mathrm{~m}^{2} \mathrm{~s}^{-1}$ and $4.04 \pm 0.16$ $\times 10^{-9} \mathrm{~m}^{2} \mathrm{~s}^{-1}$, and at $850 \mathrm{~K}, \quad D=8.85 \pm 0.16$ $\times 10^{-11} \mathrm{~m}^{2} \mathrm{~s}^{-1}$ and $3.46 \pm 0.16 \times 10^{-10} \mathrm{~m}^{2} \mathrm{~s}^{-1}$, in liquids $\mathrm{Ce}_{70} \mathrm{Cu}_{20} \mathrm{Al}_{10}$ and $\mathrm{Ce}_{70} \mathrm{Cu}_{20} \mathrm{Al}_{10} \mathrm{Nb}_{1}$, respectively. It is surprising that while adding only $1 \%$ of $\mathrm{Nb}$ the $D$ near to the melting temperature decreases by about $74 \%$. Such a large

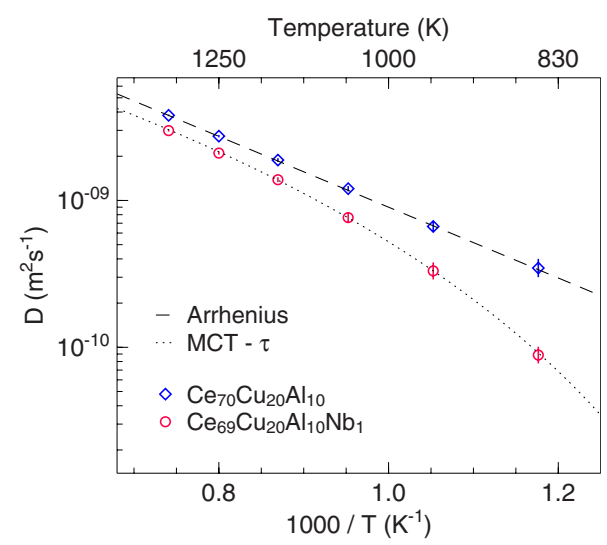

FIG. 4. (Color online) The self-diffusion of $\mathrm{Cu}$ atoms in the liquids $\mathrm{Ce}_{70} \mathrm{Cu}_{20} \mathrm{Al}_{10}$ and $\mathrm{Ce}_{69} \mathrm{Cu}_{20} \mathrm{Al}_{10} \mathrm{Nb}_{1}$ derived from the QENS data. The "straight broken" line is the Arrhenius fit to the self-diffusivity of $\mathrm{Cu}$ in liquid $\mathrm{Ce}_{70} \mathrm{Cu}_{20} \mathrm{Al}_{10}$ and dotted curve is the $\tau$-scaling fit to the selfdiffusivity of $\mathrm{Cu}$ in $\mathrm{Ce}_{69} \mathrm{Cu}_{20} \mathrm{Al}_{10} \mathrm{Nb}_{1}$ with $T_{c}=423 \mathrm{~K}$ and $\gamma=2.7$. 
change in diffusivity while microalloying was not previously observed. For example, the glass forming $\mathrm{Ni}_{59.5} \mathrm{Nb}_{40.5}$ melts while adding up to $5.2 \%$ of $\mathrm{Sn}$ increases the GFA, but $D$ did not show any significant changes. ${ }^{13}$ Moreover, in $\mathrm{Pd}_{40} \mathrm{Ni}_{40} \mathrm{P}_{20}$ replacing $\mathrm{Ni}$ by $30 \% \mathrm{Cu}$, say in $\mathrm{Pd}_{40} \mathrm{Ni}_{10} \mathrm{Cu}_{30} \mathrm{P}_{20}$, enhances the GFA significantly but $D$ measured using QENS shows a similar value at a given temperature. ${ }^{14}$ An additional surprising effect that we observed was the changes in the temperature dependent self-diffusivity. In the liquid $\mathrm{Ce}_{70} \mathrm{Cu}_{20} \mathrm{Al}_{10}, D$ shows an Arrhenius behavior but in liquid $\mathrm{Ce}_{70} \mathrm{Cu}_{20} \mathrm{Al}_{10} \mathrm{Nb}_{1}$ it becomes non-Arrhenius and can be well described by a $\tau$ scaling law of mode-coupling theory, $D \propto\left[\left(T-T_{c}\right) / T_{c}\right]^{\gamma}$. Figure 4 displays the self-diffusivities of $\mathrm{Cu}$ observed in these liquids in an Arrhenius plot. The dotted line is the $\tau$-scaling law fit to the measured self-diffusion coefficients in the liquid $\mathrm{Ce}_{70} \mathrm{Cu}_{20} \mathrm{Al}_{10} \mathrm{Nb}_{1}$ with $\left(T_{c}=1.2 T_{g}\right) T_{c}=425 \mathrm{~K}$ and $\gamma$ $=2.7$, the value for hard-sphere liquids. ${ }^{15}$ The large slowing down of self-diffusivity and transition from Arrhenius to non-Arrhenius behavior while microalloying cannot be explained by changes in the thermophysical properties or changes in the intermediate structure of the melt. However there is a clear correlation between the self-diffusivity at $T_{m}$ and the larger GFA of these metallic melts.

We suggest that the huge changes in self-diffusivity and GFA due to microalloying can only be explained by a dramatic change in the elastic stress distribution in the medium range order. A $1 \%$ change in the alloy would neither change the chemistry or the electronic system of the liquids. Elastic long range fields are known to have a large influence in the dynamic properties. ${ }^{16}$ The so called elastic stress field or compatibility stress surrounding a plastically deformed region is extremely sensitive to atoms with smaller or greater atomic ratio $(\mathrm{Ce}, \mathrm{Nb})$. These local atomic stresses are believed to create long range stress field modifications which are seen in the dynamics as well as in the GFA.

In conclusion, we have investigated dynamics in liquids $\mathrm{Ce}_{70} \mathrm{Cu}_{20} \mathrm{Al}_{10}$ and $\mathrm{Ce}_{70} \mathrm{Cu}_{20} \mathrm{Al}_{10} \mathrm{Nb}_{1}$ using QENS. We ob- served surprising effects on relaxational dynamics while microalloying the glass-forming $\mathrm{Ce}_{70} \mathrm{Cu}_{20} \mathrm{Al}_{10}$ liquid. The decay of self-correlation function extended over a wider time range. The self-diffusivity close to the melting temperature decreased by about $74 \%$ and its temperature dependence changed from Arrhenius to non-Arrhenius behavior. A detailed understanding of the reason for the above results requires new experiments and theoretical investigations concerning the elastic stress fields. However, we can show that these observations are correlated with the enhanced GFA of metallic melts.

We thank PSI for the beam time and EU-NMI3 program (FP6) for funding for the experiments. Additional support provided by the DLR through Grant No. 50WM0541, DFG SFB 602 and the Leibniz program are gratefully acknowledged.

${ }^{1}$ A. L. Greer, Science 267, 1947 (1995).

${ }^{2}$ A. Inoue, Acta Mater. 48, 279 (2000).

${ }^{3}$ W. L. Johnson, MRS Bull. 24, 42 (1999).

${ }^{4}$ D. Turnbull, Contemp. Phys. 10, 473 (1969).

${ }^{5}$ D. B. Miracle, Nature Mater. 3, 697 (2007).

${ }^{6}$ W. H. Wang, Prog. Mater. Sci. 52, 540 (2007).

${ }^{7}$ A. Mark, K. Samwer, and W. L. Jonhson, Phys. Lett. A 98, 353 (1983).

${ }^{8}$ B. Zhang, R. J. Wang, D. Q. Zhao, M. X. Pan, and W. H. Wang, Phys. Rev. B 73, 092201 (2006).

${ }^{9}$ B. Zhang, D. Q. Zhao, M. X. Pan, R. J. Wang, and W. H. Wang, Acta Mater. 54, 3025 (2006)

${ }^{10}$ W. Götze and L. Sjögren, Rep. Prog. Phys. 55, 241 (1992).

${ }^{11}$ S. K. Das, J. Horbach, M. M. Koza, S. M. Chathoth, and A. Meyer, Appl. Phys. Lett. 86, 011918 (2005).

${ }^{12}$ J. P. Boon and S. Yip, Molecular Hydrodynamics (McGraw-Hill, New York, 1980).

${ }^{13}$ S. M. Chathoth, B. Damaschke, M. M. Koza, and K. Samwer, Phys. Rev. Lett. 101, 037801 (2008)

${ }^{14}$ S. M. Chathoth, A. Meyer, M. M. Koza, and F. Juranyi, Appl. Phys. Lett. 85, 4881 (2004).

${ }^{15}$ M. Fuchs, I. Hofacker, and A. Latz, Phys. Rev. A 45, 898 (1992).

${ }^{16}$ W. L. Johnson and K. Samwer, Phys. Rev. Lett. 95, 195501 (2005). 